\title{
Occurrence of Double Bond in $\pi$-Aromatic Rings: An Easy Way to Design Doubly Aromatic Carbon-Metal Structures
}

\author{
Nikolay V. Tkachenko ${ }^{1,2}$, Alvaro Muñoz-Castro ${ }^{2}$ and Alexander I. Boldyrev ${ }^{1, *}$ \\ 1 Department of Chemistry and Biochemistry, Utah State University, 0300 Old Main Hill, \\ Logan, UT 84322-0300, USA; nikolay.tkachenko95@gmail.com \\ 2 Grupo de Química Inorgánica y Materiales Moleculares, Facultad de Ingeniería, Universidad Autonoma de \\ Chile, El Llano Subercaseaux, Santiago 2801, Chile; alvaro.munoz@uautonoma.cl \\ * Correspondence: a.i.boldyrev@usu.edu
}

check for updates

Citation: Tkachenko, N.V.;

Muñoz-Castro, A.; Boldyrev, A.I.

Occurrence of Double Bond in

$\pi$-Aromatic Rings: An Easy Way to

Design Doubly Aromatic

Carbon-Metal Structures. Molecules

2021, 26, 7232. https://doi.org/

$10.3390 /$ molecules 26237232

Academic Editors: Xin Liu and Ángel Martín Pendás

Received: 7 November 2021

Accepted: 26 November 2021

Published: 29 November 2021

Publisher's Note: MDPI stays neutral with regard to jurisdictional claims in published maps and institutional affiliations.

Copyright: (C) 2021 by the authors. Licensee MDPI, Basel, Switzerland. This article is an open access article distributed under the terms and conditions of the Creative Commons Attribution (CC BY) license (https:/ / creativecommons.org/licenses/by/ $4.0 /)$.

\begin{abstract}
A chemical bonding of several metallabenzenes and metallabenzynes was studied via an adaptive natural density partitioning (AdNDP) algorithm and the induced magnetic field analysis. A unique chemical bonding pattern was discovered where the $\mathrm{M}=\mathrm{C}(\mathrm{M}$ : Os, Re) double bond coexists with the delocalized $6 c-2 e \pi$-bonding elements responsible for aromatic properties of the investigated complexes. In opposition to the previous description where 8 delocalized $\pi$-electrons were reported in metallabenzenes and metallabenzynes, we showed that only six delocalized $\pi$ electrons are present in those molecules. Thus, there is no deviation from Hückel's aromaticity rule for metallabenzynes/metallabenzenes complexes. Based on the discovered bonding pattern, we propose two thermodynamically stable novel molecules that possess not only $\pi$-delocalization but also retain six $\sigma$-delocalized electrons, rendering them as doubly aromatic species. As a result, our investigation gives a new direction for the search for carbon-metal doubly aromatic molecules.
\end{abstract}

Keywords: aromaticity; double-aromaticity; metallabenzynes; Hückel's aromaticity rule

\section{Introduction}

Since the pioneering work of Thorn and Hoffmann investigating the delocalization in metallocycles [1], and a consequent isolation of osmebenzene by Roper et al. [2], a huge variety of metalla-aromatic structures have been discovered experimentally and studied computationally [3-9]. Those species can be described as usual aromatic compounds where one or several carbon atoms are replaced with a transition metal atom. Such a peculiar combination of a transition metal and a carbon-framework can produce a variety of interesting chemical bonding patterns. The study of metallocycles is important not only for the broad understanding of chemical bonding concepts and applicability of the aromaticity term but also as useful for synthetic organic chemistry [10-13].

One very important subgroup of metalla-aromatics is metallabenzenes (Figure 1a), metallacycle analogs to benzene. Chemists have managed to synthesize a huge variety of these complexes, incorporating various metals into the aromatic ring such as: osmium [14-23], rhenium [24-26], platinum [27-30], and iridium [31-37]. It was shown that metallabenzenes bear an appreciable aromatic character which is reflected in rather high aromatic stabilization energies [38-41] and negative nucleus-independent chemical shift values [42-45]. In the work of Thorn and Hoffmann, authors suggested that the metallabenzenes should have six $\pi$ electrons, two of which come from the metal atom ( $\mathrm{d}_{\mathrm{xz}}$ orbital), while the remaining 4 electrons come from the $\mathrm{C}_{5} \mathrm{H}_{5}{ }^{-}$fragment [1]. Martin et al. showed a cognate conclusion, noting a striking similarity between orbitals of benzene and metallabenzenes [44]. Interestingly, more recent studies do not share this point of view, introducing different numbers of delocalized $\pi$-electrons. Thus, Schleyer proposed that the $\mathrm{d}_{\mathrm{yz}}$ orbital is also participating in $\pi$-delocalization, and, thus, eight $\pi$-electrons are delocalized in the $\pi$-system [3]. This result contradicts with the Hückel $[4 n+2]$ aromaticity rule; however, authors discussed that 
only two delocalized orbitals have the Hückel character, while another two orbitals (where the $\mathrm{d}_{\mathrm{yz}}$ orbital participates in delocalization) have the Möbius character [46] for which Hückel's rule does not work. Later, Fernandez and Frenking proposed their interpretation of metallabenzenes aromaticity, showing the presence of ten $\pi$-electrons, where $p$-orbitals of in-plane ligands also participate in the $\pi$-delocalization [38,47]. All alternative interpretations were based on the analysis of canonical molecular orbitals (MOs) and studied the degree of stabilization that comes from the metal $d$-orbitals. In this work, we are trying to address this issue with the AdNDP localization technique that can explicitly show the degree of delocalization within the metallacycle.
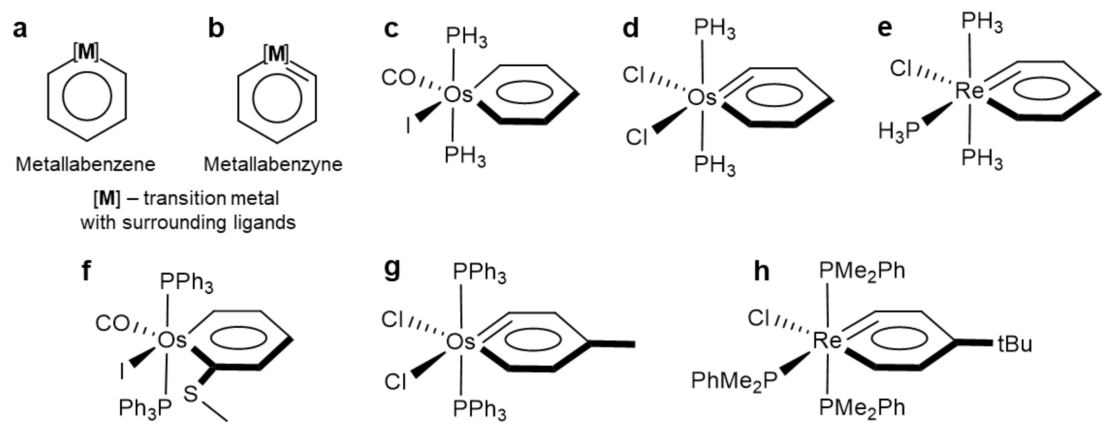

Figure 1. Structures of metallabenzenes and metallabenzynes. Structures (a) and (b) are general structures of metallabenzenes and metallabenzynes, respectively. Structures (c-e) are considered in this study and are model structures for previously synthesized complexes $(\mathbf{f}-\mathbf{h})$.

Another quite intriguing subgroup of the metalla-aromatic compound is metallabenzynes (Figure 1b). Those complexes are of particular interest since they combine the double $\mathrm{M}=\mathrm{C}$ bond and $\pi$-conjugated aromatic ring. Such a peculiar chemical bonding regime can help design new molecules with unprecedented physical and chemical properties.

In this study, we analyze the chemical bonding patterns of various model metallabenzene and metallabenzyne complexes (Figure 1c-e) which are analogues of experimentally synthesized complexes (Figure 1f-h) $[14,48,49]$. From the AdNDP analysis, only six $\pi$ electrons were found to participate in the delocalization in both metallabenzenes and metallabenzynes, agreeing with the Thorn and Hoffmann description. Based on the chemical bonding analysis of osmabenzyne and rhenabenzyne, two novel structures that possess doubly aromatic six-membered carbon-metal ring were designed.

\section{Theoretical Methods}

All structures were initially preoptimized using a PBE0 [50] DFT functional and LANL2DZ [51] basis set. Subsequent refinement of structural data was conducted using a large def2-TZVP [52] basis set. A chemical bonding analysis was performed using the AdNDP $[53,54]$ algorithm as implemented in AdNDP 2.0 code. The AdNDP method can represent a chemical bonding pattern in terms of both Lewis bonding elements (lone pairs (1c-2e) and 2c-2e bonds) as well as delocalized bonding elements (such as nc-2e $(n>2)$ bonds), allowing one to describe highly delocalized electrons associated with the concept of aromaticity. This technique is widely used in describing chemical bonding patterns of various metal-containing clusters [55-60], aromatic 2D-materials [61-63], and doubly aromatic metal systems $[64,65]$. All AdNDP calculations were performed at the PBE0/def2-TZVP level of theory. It was shown before that the PBE0 functional could overestimate electron delocalization and aromaticity in planar aromatic systems [66]. To avoid this problem, we reoptimized geometries and performed the AdNDP analysis using the CAM-B3LYP functional [67] that does not suffer from a delocalization error. We note that the obtained AdNDP results reproduce results obtained with the PBE0 functional showing that the found chemical bonding pattern is DFT-functionally independent. The frequency calculations were performed using the harmonic approximation, and all reported structures were confirmed to be minimal due to the absence of imaginary frequencies. To 
assess the aromaticity with a quantitative parameter, NICS [68] calculations were performed at the PBE0/def2-TZVP level. The ChemCraft 1.8 software was used to visualize chemical bonding patterns and geometries of investigated compounds. The Gaussian 16 software was used for all quantum chemical calculations described above [69].

The nucleus-independent shielding tensors $\left(\sigma_{\mathrm{ij}}\right)$ [70-72] were calculated within the GIAO formalism by using the ADF2019 code [73], employing the hybrid PBE0 [50] functional and an all-electron STO-TZ2P basis set, placed in a three-dimensional grid in order to evaluate the induced field $\left(\mathrm{B}^{\mathrm{ind}}\right)$, upon an external magnetic field $\left(\mathrm{B}^{\mathrm{ext}}\right)$, related via $\mathrm{B}_{\mathrm{i}}{ }^{\text {ind }}=-\sigma_{\mathrm{ij}} \mathrm{B}_{\mathrm{j}}^{\mathrm{ext}}$ [74-76]. For convenience, the $\mathrm{i}$ and $\mathrm{j}$ suffixes are related to the $\mathrm{x}^{-}, \mathrm{y}^{-}$, and $z$-axes of the molecule-fixed Cartesian system $(i, j=x, y, z)$. The values of $B^{\text {ind }}$ are given in ppm in relation to $B^{\text {ext }}$. Relativistic effects were considered through the ZORA Hamiltonian [77].

\section{Results and Discussion}

\subsection{Hückel's [4n+2] $\pi$-Aromaticity of Metallabenzenes and Metallabenzynes}

To model the synthesized rhenium and osmium complexes (Figure $1 \mathrm{f}-\mathrm{h}$ ), we replaced bulky $\mathrm{Ph}_{3} \mathrm{P}$ - and $\mathrm{PhMe}_{2} \mathrm{P}$ - groups with a $\mathrm{PH}_{3}$ - ligand, while we preserve all atoms in the aromatic rings as they are in the experimental structure. Such a substitution does not affect chemical bonding in the metallocycle itself and will reflect the delocalization pattern properly. The optimized geometries reproduce the $\mathrm{M}-\mathrm{C}(\mathrm{M}$ : Os, $\mathrm{Re}$ ) and C-C distances within the aromatic ring with a good precision (bond lengths' deviations from the experimental data are within the $0.1-0.01 \AA$ range). The alternation of $\mathrm{C}-\mathrm{C}$ inside the ring is not large, and all bonds have the same length within the $\sim 0.03 \AA$ for Os structures and $\sim 0.05 \AA$ for the Rhenium complex. To ensure that the constructed single-determinant singlet wavefunction can be applied in those cases, we checked the stability of the wave function (WF) showing the absence of any RKS to UKS instabilities. We also performed the optimization of the complexes in the triplet open-shell configuration and found the triplet states are appreciably higher in energy than the singlet states. Those facts show that the DFT approximation is valid in this case, and the singlet single-determinant WF could be used to describe the systems considered. For the sake of simplicity, we introduce the following notation for the investigated complexes: $\left[\mathrm{Os}(\mathrm{CO}) \mathrm{I}\left(\mathrm{PH}_{3}\right)_{2}\left(\mathrm{C}_{5} \mathrm{H}_{5}\right)\right]-[\mathrm{Os}] \mathrm{C}_{5} \mathrm{H}_{5}$, $\left[\mathrm{OsCl}_{2}\left(\mathrm{PH}_{3}\right)_{2}\left(\mathrm{C}_{5} \mathrm{H}_{4}\right)\right]-[\mathrm{Os}] \mathrm{C}_{5} \mathrm{H}_{4}$, and $\left[\mathrm{ReCl}\left(\mathrm{PH}_{3}\right)_{3}\left(\mathrm{C}_{5} \mathrm{H}_{4}\right)\right]-[\mathrm{Re}] \mathrm{C}_{5} \mathrm{H}_{4}$.

To analyze the chemical bonding in the investigated species, we performed an AdNDP analysis as implemented in AdNDP 2.0 code. We start our discussion with the chemical bonding of the osmabenzene. The $[\mathrm{Os}] \mathrm{C}_{5} \mathrm{H}_{5}$ complex has 66 valence electrons that could be localized into 33 two-electron bonding elements. Following the idea of AdNDP analysis, the localization starts from the one-center two-electron (1c-2e) elements, or lone pairs. We found two s-type lone pairs on oxygen and iodine atoms with occupation numbers (ON) 2.00-1.98 le l, two $p$-type lone pairs on iodine with $\mathrm{ON}=1.99-1.93$ le $\mathrm{l}$, and two $d$-type lone pairs $\left(d_{\mathrm{yz}}\right.$ and $\left.d_{\mathrm{x} 2-\mathrm{y} 2}\right)$ on the Os-atom with $\mathrm{ON}=1.78-1.75$ I e I (Figure 2a). A consequent localization of $2 \mathrm{c}-2 \mathrm{e}$ bonding elements leads to a $\sigma$-bonding framework with sixteen $\mathrm{C}-\mathrm{O}, \mathrm{C}-\mathrm{C}, \mathrm{C}-\mathrm{H}$, and $\mathrm{P}-\mathrm{H}$ 2c-2e bonds with $\mathrm{ON}=2.00-1.97 \mathrm{l}$ e I. The Osmium atom has a quasi-octahedral environment, and six Os-C, Os-P, and Os-I 2c-2e $\sigma$-bonds with $\mathrm{ON}=1.98-1.93$ | e | can be localized. Predictably, two $2 \mathrm{c}-2 \mathrm{e} \pi$-bonds were found in the $-\mathrm{C} \equiv \mathrm{O}$ ligand rendering the $\mathrm{C}-\mathrm{O}$ bond as a triple bond. The remaining six valence electrons form $\pi$-delocalized $6 c-2 e$ bonds, resembling benzene $6 c-2 e$ delocalization (Figure $2 a)$. The shape of those bonds and the number of electrons (in agreement with the Hückel's [4n+2] rule) render this complex as $\pi$-aromatic. The complete bonding pattern of [Os] $\mathrm{C}_{5} \mathrm{H}_{5}$ can be found in the Supporting Information file (Figure S1), while the most significant bonding elements are shown in Figure 2a. 


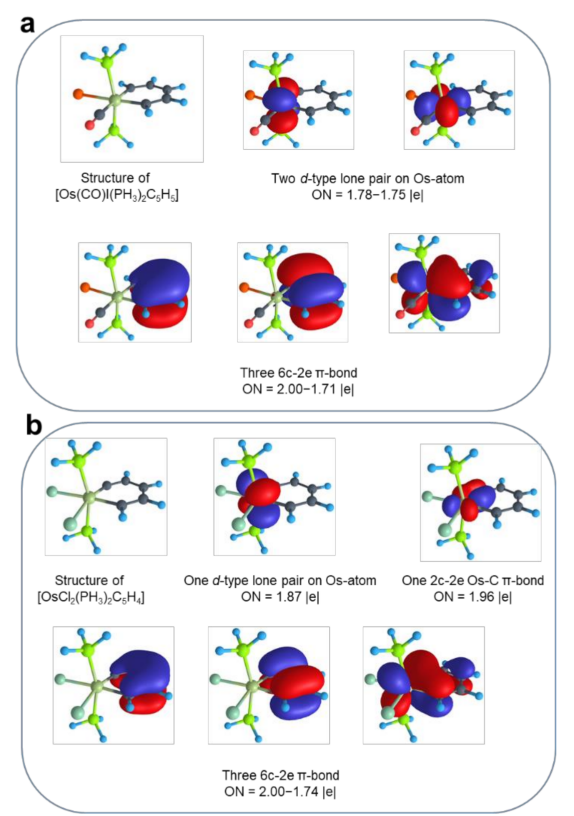

Figure 2. Results of the AdNDP analysis for $\left[\mathrm{Os}(\mathrm{CO}) \mathrm{I}\left(\mathrm{PH}_{3}\right)_{2}\left(\mathrm{C}_{5} \mathrm{H}_{5}\right)\right](\mathbf{a})$ and $\left[\mathrm{OsCl}_{2}\left(\mathrm{PH}_{3}\right)_{2}\left(\mathrm{C}_{5} \mathrm{H}_{4}\right)\right]$ (b). Only selected bonding elements are shown.

We want to note that this picture contradicts with some recent descriptions of metallabenzenes, where eight [3] and ten $[38,47] \pi$-electrons were meant to be delocalized in the metallocycle. It was discussed that not only the $d_{\mathrm{xz}}$ orbital of the Os-atom participates in the formation of $\pi$-conjugation, but also the $d_{\mathrm{yz}}$ orbital overlaps with the $\pi$-electrons of the carbon framework. However, this conclusion was made based on the canonical molecular orbital (MO) picture, which is delocalized in its nature. We believe that the picture obtained by the AdNDP is more chemically intuitive and more descriptive since it is based on the matrix representation of the first-order reduced density operator. We can definitely localize the $d_{\mathrm{yz}}$ lone pair on the Os-atom which does not participate in delocalization in any significant manner, although it is formally of the same symmetry as some orbitals in the $\pi$-conjugated system. To show that, we localized this lone pair as a $6 c-2 e \pi$-bond. The increase in ON was only $0.1 \mathrm{l}$ e $\mathrm{I}$ showing a tiny degree of the delocalization of the $d_{\mathrm{yz}}$ lone pair over the metallabenzene ring. Thus, we believe that the initial description proposed by Thorn and Hofmann is correct, and there is no deviation from Hückel's aromaticity rule for metallabenzynes/metallabenzenes complexes.

A cognate chemical bonding was found for the $[\mathrm{Os}] \mathrm{C}_{5} \mathrm{H}_{4}$ complex (Figure S2). The main difference in chemical bonding is the presence of a 2c-2e Os-C in-plane $\pi$-bond (Figure $2 b$ ), which is also reflected in the significant shortening of Os=C distance with respect to the Os-C single-bond ( $\sim 27 \AA$ difference). A similar chemical bonding pattern was found for rhenabenzyne (Figure S3). It is a very intriguing result, since, to the best of our knowledge, the coexistence of the in-plane $\pi$-bond with the $\pi$-aromatic system has never been described before in the realms of the AdNDP localization technique. The possibility of such a reconciliation opens up an opportunity to design quite unique structures with doubly aromatic metal-carbon rings that will be described in the next subsection.

\subsection{Hückel's $[4 n+2] \sigma$-and $\pi$-Double Aromaticity of Novel Carbon-Metal Structures}

The possibility to use the in-plane $p$-orbital of carbon and $d_{\mathrm{x} 2 \text {-y2 }}$-orbital of the transition metal without the introduction of a huge strain (in comparison to the case of the planar benzyne $\mathrm{C}_{6} \mathrm{H}_{4}$ ring, where a highly strained $\mathrm{C} \equiv \mathrm{C}$ bond is present) allows proposing possible metal-carbon structures that will employ delocalization not only in the $\pi$-fashion but also in the $\sigma$-regime. As illustrated in Figure 3, the combination of three carbon atoms and three transition metal atoms could potentially produce a stable doubly aromatic six-membered ring. 


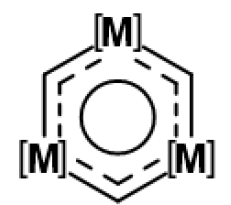

Doubly-aromatic $[\mathrm{M}]_{3} \mathrm{C}_{3}$

[M] - transition metal with surrounding ligands

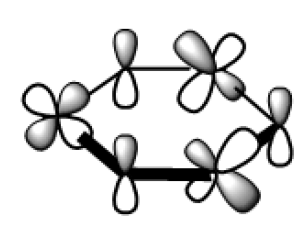

Six delocalized $\pi$-electrons

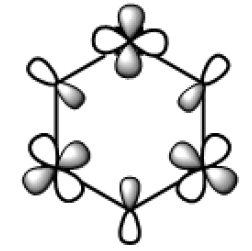

Six delocalized

$\sigma$-electrons

Figure 3. Proposed structure of doubly aromatic metal-carbon ring and orbitals' representation of conjugated $\pi$ - and $\sigma$ - electrons.

To test this hypothesis, we employed the [M] motifs ([M]: $\left.\left[\mathrm{OsCl}_{2}\left(\mathrm{PH}_{3}\right)_{2}\right],\left[\mathrm{ReCl}\left(\mathrm{PH}_{3}\right)_{3}\right]\right)$ that were used in the first part of this work and combined them with three carbon atoms to form a six-membered ring. As a result, $\left[\left\{\mathrm{OsCl}_{2}\left(\mathrm{PH}_{3}\right)_{2}\right\}_{3} \mathrm{C}_{3}\right]\left([\mathrm{Os}]_{3} \mathrm{C}_{3}\right)$ and $\left[\left\{\mathrm{ReCl}\left(\mathrm{PH}_{3}\right)_{3}\right\}_{3} \mathrm{C}_{3}\right]$ $\left([\operatorname{Re}]_{3} \mathrm{C}_{3}\right)$ stoichiometries were obtained. The optimized structures are found to be a local minimum without possessing any imaginary frequencies. The WF was checked to be stable, and similar triplet species are significantly higher in energy than the singlet ones. The geometries of the proposed species are shown in Figure 4. Remarkably, both structures contain the $\mathrm{M}_{3} \mathrm{C}_{3}$ six-membered planar ring.
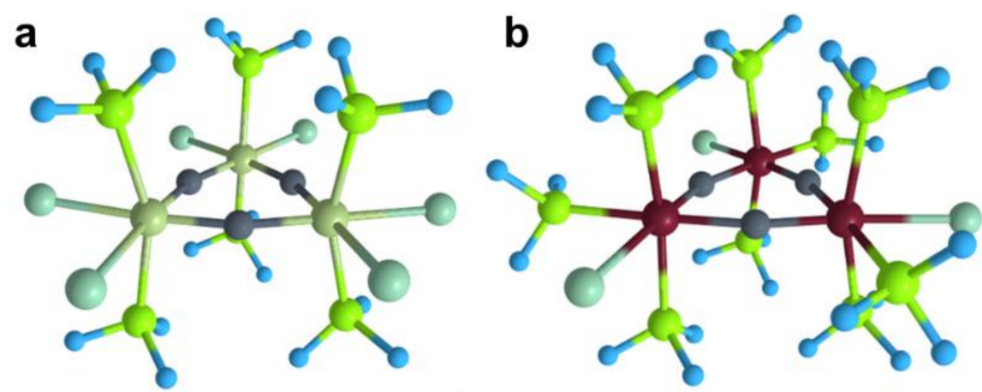

Figure 4. Optimized structures of proposed doubly aromatic complexes: $[\mathrm{Os}]_{3} \mathrm{C}_{3}(\mathbf{a})$ and $[\operatorname{Re}]_{3} \mathrm{C}_{3}(\mathbf{b})$.

The AdNDP analysis reveals the cognate chemical bonding pattern as was found in metallabenzynes. The localized lone pairs and $\sigma$-bonding framework coincide (Figures S4 and S5). However, the remaining 12 electrons form three delocalized 6c-2e $\sigma$ - and $\pi$-bonding elements (Figure 5 ). The shape of those elements agrees with the proposed model bonding depicted in Figure 3. We note that the occupation numbers of $\pi$-aromatic bonds are rather low $\left(1.68-1.55|\mathrm{e}|\right.$ for $[\mathrm{Os}]_{3} \mathrm{C}_{3}$ and $1.79-1.74|\mathrm{e}|$ for $\left.[\mathbf{R e}]_{3} \mathrm{C}_{3}\right)$; however, the occupancies could be increased up to $2.00-1.98$ I e I values by including phosphorous atoms in the localization scheme (resulting in 12c-2e bonds). Thus, 6c-2e $\pi$-bonds show some delocalization character over $-\mathrm{PH}_{3}$ ligands. Previously, the presence of double aromaticity in metal systems was discussed for $\mathrm{M}_{4}{ }^{2-}$ molecules composed out of $\mathrm{Al}$, $\mathrm{Ga}$, and In atoms $[64,65]$. Moreover, recently, Saito and coworkers synthesized a molecule $\left(\left[\mathrm{C}_{6}(\mathrm{SePh})_{6}\right]\left[\mathrm{SbF}_{6}\right]_{2}\right)$ in an isolated form that possesses a double aromaticity arising from $\sigma$ and $\pi$-rings [78]. 


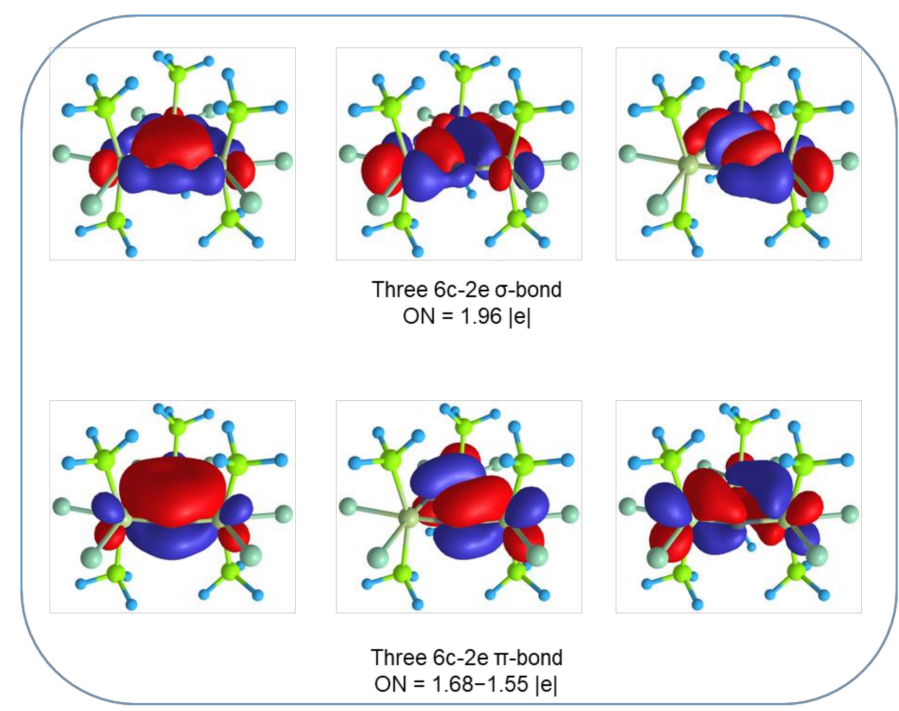

Figure 5. Results of the AdNDP analysis for $[\mathrm{Os}]_{3} \mathrm{C}_{3}$. Only $\sigma$ - and $\pi$ - delocalized bonding elements are shown. The cognate pattern was found for $[\mathbf{R e}]_{3} C_{3}$.

To assess the aromaticity of metallo-organic rings with a quantitative parameter, we calculated $\operatorname{NICS}_{z z}(0)$ and $\operatorname{NICS}_{z z}(1)$ indices (Table 1) at the center of the aromatic rings. The exact coordinates of the special points for each cluster can be found in the Supporting Information file (Table S2). The significantly low values of $\operatorname{NICS}_{\mathrm{zz}}(0)$ and $\mathrm{NICS}_{\mathrm{zz}}(1)$ indices inside of aromatic rings and the increasing of the $\operatorname{NICS}_{z z}(0)$ values for $[M]_{3} C_{3}$ species are in agreement with the overall description of double aromaticity in the proposed structures and $\pi$-aromaticity of the metallabenzenes and metallabenzynes species.

Table 1. NICS ${ }_{z Z}(0)$ and NICS $(1)$ indices calculated for complexes investigated in this work.

\begin{tabular}{ccc}
\hline Complex & NICS $_{\mathbf{z z}}(\mathbf{0})$ & NICS $_{\mathbf{z z}}(\mathbf{1})$ \\
\hline$[\mathrm{Os}] \mathrm{C}_{5} \mathrm{H}_{4}$ & -9.2 & -15.0 \\
{$[\operatorname{Re}] \mathrm{C}_{5} \mathrm{H}_{4}$} & -9.9 & -14.2 \\
{$[\mathrm{Os}]_{3} \mathrm{C}_{3}$} & -23.5 & -2.8 \\
{$[\operatorname{Re}]_{3} \mathrm{C}_{3}$} & -29.5 & -6.3 \\
\hline
\end{tabular}

We note that the difference in the trends for $\operatorname{NICS}_{z z}(0)$ and $\operatorname{NICS}_{z z}(1)$ for $[\mathbf{M}] \mathrm{C}_{5} \mathrm{H}_{4}$ and $[\mathrm{M}]_{3} \mathrm{C}_{3}$ is due to the different types of aromaticity that are present in those systems. Since $[\mathbf{M}] \mathrm{C}_{5} \mathrm{H}_{4}$ is a $\pi$-aromatic system, we observe that $\mathrm{NICS}_{\mathrm{zz}}(0)$ values are less negative than $\mathrm{NICS}_{\mathrm{zz}}(1)$ values (a similar trend can be found in $\pi$-aromatic benzene). In turn, $[\mathbf{M}]_{3} \mathrm{C}_{3}$ systems are doubly aromatic and possess $\sigma$-aromaticity in addition to $\pi$ aromaticity. For $\sigma$-aromatic systems, it was found before that $\mathrm{NICS}_{\mathrm{zz}}(0)$ is more negative than $\operatorname{NICS}_{z z}(1)[79,80]$. Thus, due to the presence of $\sigma$-aromaticity, $[\mathbf{M}]_{3} C_{3}$ systems possess largely negative $\operatorname{NICS}_{z z}(0)$. Such a trend could be vividly visualized using $\mathrm{NICS}_{z z}$-Scan plots (Figure S6). Slightly less negative values of $\mathrm{NICS}_{\mathrm{zz}}(1)$ of $[\mathbf{M}]_{3} \mathrm{C}_{3}$ in comparison with $[\mathrm{M}] \mathrm{C}_{5} \mathrm{H}_{4}$ are due to the delocalization of $\pi$-electrons to the $-\mathrm{PH}_{3}$ ligands, which is also reflected in the ONs of $\pi$-delocalized bonds obtained from the AdNDP analysis.

To access the spatial distribution of the magnetic shielding parameters, the isosurface representation of the induced magnetic field $\left(B_{\text {ind }}\right)$ was calculated. It accounts for the characteristic patterns of the magnetic response at the molecular surroundings of the complexes, revealing the inherent characteristics given by the above discussed bonding pattern related to the Hückel's [ $4 n+2]$ aromaticity on the studied metallobenzynes and metallabenzenes complexes. The isotropic term is related to the orientational averaged response owing to the molecular tumbling in solution, which is related to NICS given as an isosurface along the overall structure denoted as Iso (Figure 6), which shows a larger contribution from the $\mathrm{M}-\mathrm{C}, \mathrm{M}-\mathrm{Cl}$, and $\mathrm{M}-\mathrm{P}$ bond $(\mathrm{M}=\mathrm{Os}, \mathrm{Re})$. In addition, for $[\mathrm{Os}] \mathrm{C}_{5} \mathrm{H}_{4}$ 
and $[\operatorname{Re}] \mathrm{C}_{5} \mathrm{H}_{4}$, a shielding surface at the six membered $\mathrm{MC}_{5} \mathrm{H}_{4}$ ring indicates its aromatic character. In agreement to $\operatorname{NICS}_{\mathrm{zz}}(0)$ and $\operatorname{NICS}_{\mathrm{zz}}(1)$ values (Table 1 ), the related $\mathrm{B}_{\mathrm{z}}$ ind isosurface exhibits an enhanced shielding response with a complementary deshielding region along the ring backbone, denoting the shielding cone property from aromatic rings. The contour plot for $B_{z}$ ind supports this behavior, showing a shielding value of $\sim-10$ ppm nearby the center of the ring increasing along the $z$-axis, which is enhanced towards the $\mathrm{C}-\mathrm{C}$ and $\mathrm{C}-\mathrm{M}$ bonds (>-20 ppm).

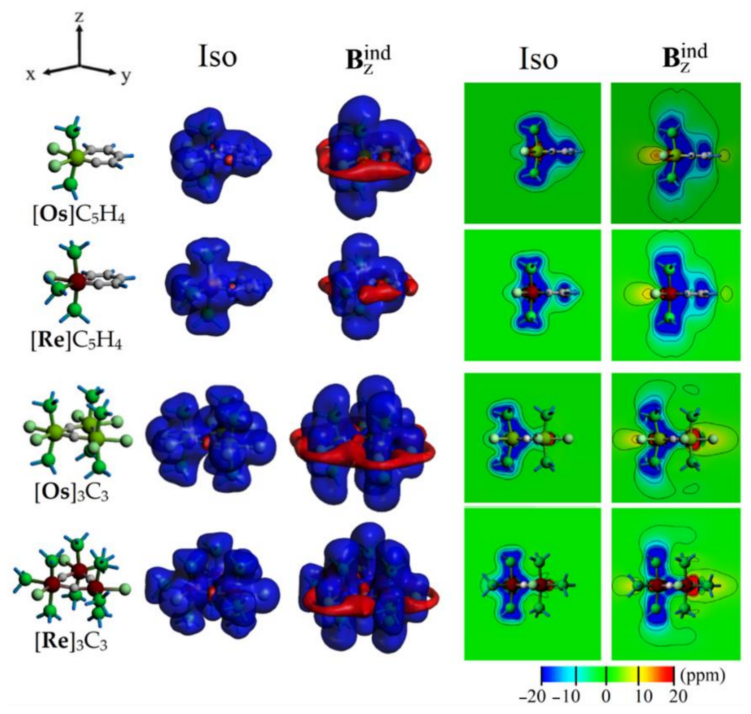

Figure 6. The induced magnetic field for $[\mathrm{Os}] \mathrm{C}_{5} \mathrm{H}_{4},[\operatorname{Re}] \mathrm{C}_{5} \mathrm{H}_{4},[\mathrm{Os}]_{3} \mathrm{C}_{3}$, and $[\operatorname{Re}]_{3} \mathrm{C}_{3}$, given as isosurface ( \pm 5 ppm, Blue: Shielding; Red: Deshielding) and contour plot (Side-view; Negative values: Shielding; positive: Deshielding).

For $[\mathrm{Os}]_{3} \mathrm{C}_{3}$ and $[\operatorname{Re}]_{3} \mathrm{C}_{3}$ rings, the $\mathrm{NICS}_{\mathrm{zz}}(0)$ values (Table 1 ) show an enhanced shielding denoting their double aromatic characteristics. Similarly, the isosurface and contour plot representation of Iso and $\mathrm{B}_{\mathrm{Z}}$ ind denotes an enhanced shielding response at the center of the $\mathrm{M}_{3} \mathrm{C}_{3}$ ring, in comparison to the $\mathrm{MC}_{5} \mathrm{H}_{4}$ case, which is decreased along the $z$-axis as previously depicted by $\mathrm{NICS}_{\mathrm{zz}}(1)$. Moreover, nearby the $\mathrm{M}$ center, a deshielding contribution is found, suggesting that besides the double aromatic character of the $\mathrm{M}_{3} \mathrm{C}_{3}$ ring, the $\mathrm{NICS}_{\mathrm{zz}}$ values are also affected by the contribution from the metal center, leading to a decrease in the shielding behavior nearby the center of the $[\mathrm{Os}]_{3} C_{3}$ and $[\operatorname{Re}]_{3} C_{3}$ rings, as shown from the side-view contour plot of $B_{z}$ ind from Figure 6 , but clarified by the top-view from Figure 7. It is important to note that such an observation is exclusive for metal-containing rings in contrast to hydrocarbons or other light element structures because of the contribution from core electrons [81].

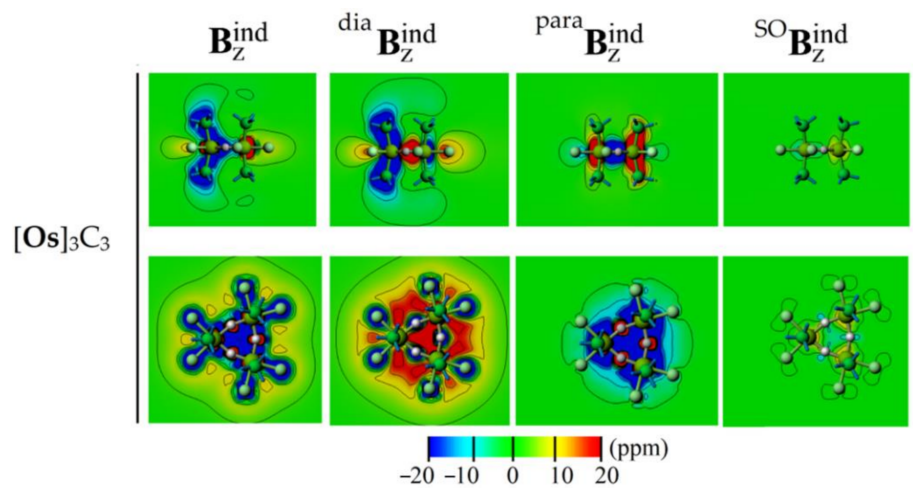

Figure 7. The induced magnetic field for $[\mathrm{Os}]_{3} \mathrm{C}_{3}$, given as contour plot and its contribution from diamagnetic ( $\left.{ }^{\text {dia }} \mathrm{B}_{\mathrm{Z}}{ }^{\text {ind }}\right)$, paramagnetic ( $\left.{ }^{\text {ara }} \mathrm{B}_{\mathrm{Z}}{ }^{\text {ind }}\right)$, and spin-orbit $\left({ }^{\mathrm{SO}_{\mathrm{B}}}{ }^{\text {ind }}\right)$ terms. 
Furthermore, the contribution from the metal center to the $\mathrm{NICS}_{\mathrm{zz}}$ and its related isosurface $\left(\mathrm{B}_{z}{ }^{\text {ind }}\right)$ terms is explored in terms of diamagnetic ( ${ }^{\text {dia }} \mathrm{B}_{z}{ }^{\text {ind }}$ ), paramagnetic ( ${ }^{\text {para }} \mathrm{B}_{z}{ }^{\text {ind }}$ ), and spin-orbit $\left({ }^{{ }^{S O}} \mathrm{~B}_{\mathrm{Z}}{ }^{\text {ind }}\right)$ contributions within the two components' ZORA/GIAO formalism [82].

$$
\mathrm{B}_{\mathrm{Z}}{ }^{\text {ind }}={ }^{\text {dia }} \mathrm{B}_{\mathrm{Z}} \text { ind }+{ }^{\text {para }} \mathrm{B}_{\mathrm{Z}}{ }^{\text {ind }}+{ }^{\mathrm{SO}} \mathrm{B}_{\mathrm{Z}} \text { ind }
$$

The diamagnetic contribution involves an unperturbed electron density and is largely affected by the number of core electrons, thus increasing according to the atomic number $(\mathrm{Z})$ of the involved metal centers [82]. The paramagnetic term $\left({ }^{\mathrm{para}} \mathrm{B}_{\mathrm{z}}{ }^{\text {ind }}\right)$ involves the mixing of ground and excited states upon the external magnetic field, and is mainly affected by the frontier orbital structure, and thus accounting for the classical electron counting consideration, such as Hückel's rule. Lastly, the spatial contribution from the spin-orbit coupling is accounted by the ${ }^{{ }^{\mathrm{SO}}} \mathrm{B}_{\mathrm{z}}$ ind term [83].

From Figure 7, the strong shielding behavior at the center of the $\mathrm{Os}_{3} \mathrm{C}_{3}$ ring is contributed from the paramagnetic term, i.e., accounting for the favorable double aromatic character, as depicted by the bonding pattern fulfilling both in-plane and out-of-plane Hückel circuits. Interestingly, the diamagnetic contribution shows a large deshielding contribution originated at each $\mathrm{M}$ center, with a small ${ }^{\mathrm{SO}_{\mathrm{Z}}}$ ind contribution. Hence, the contribution from core electrons from $\mathrm{M}$ decreases the long range characteristics of the shielding cone property [84] of the $\mathrm{Os}_{3} \mathrm{C}_{3}$ ring. Similar results were obtained for $[\operatorname{Re}]_{3} \mathrm{C}_{3}$ (Figure S7).

\section{Conclusions}

In this research we showed that metallobenzynes and metallabenzenes complexes possess Hückel's [ $4 n+2]$ classical $\pi$-aromatic conjugated system. We showed that the previous assignment of eight and ten delocalized $\pi$-electrons does not agree with the AdNDP localization picture, and the $d_{\mathrm{yz}}$ lone pair of a transition metal has an appreciable occupation number and cannot be considered as a delocalized $6 c-2 e$ bond. By analyzing chemical bonding of metallabenzynes, we firstly described an in-plane $\pi$-bond coexisting with $\pi$-aromaticity in realms on the AdNDP analysis. It allowed us to construct two novel molecules ([Oss $]_{3} \mathrm{C}_{3}$ and $[\mathrm{Re}]_{3} \mathrm{C}_{3}$ ) with doubly aromatic six-membered ring, denoting the contribution from the metal core electrons to the magnetic characteristics of the overall structure. We believe these findings will help in the development and understanding of chemical bonding in metallocycles and open a possibility to discover a novel class of doubly aromatic carbon-metal species.

Supplementary Materials: Figure S1: Chemical bonding pattern of [Os $] \mathrm{C}_{5} \mathrm{H}_{5}$, Figure S2: Chemical bonding pattern of $[\mathrm{Os}] \mathrm{C}_{5} \mathrm{H}_{4}$, Figure S3: Chemical bonding pattern of $[\mathrm{Re}] \mathrm{C}_{5} \mathrm{H}_{4}$, Figure S4: Chemical bonding pattern of $[\mathbf{O s}]_{3} C_{3}$, Figure S5: Chemical bonding pattern of $[\mathbf{R e}]_{3} \mathrm{C}_{3}$, Figure S6: The $\mathrm{NICS}_{\mathrm{zz}}$ values calculated at different distances from the ring center, Figure S7: The induced magnetic field for investigated complexes, Table S1: Optimized structures of investigated complexes, Table S2: Coordinates of chosen points for NICS calculation.

Author Contributions: Conceptualization, N.V.T., A.M.-C. and A.I.B.; methodology, N.V.T., A.M.-C. and A.I.B.; writing-original draft preparation, N.V.T., A.M.-C. and A.I.B.; writing-review and editing, N.V.T., A.M.-C. and A.I.B.; visualization, N.V.T., A.M.-C. and A.I.B.; supervision, A.I.B.; All authors have read and agreed to the published version of the manuscript.

Funding: The research was funded by the R. Gaurth Hansen Professorship fund to A.I.B.; A.M.-C. acknowledges financial support from the FONDECYT/ANID grant 1180683.

Institutional Review Board Statement: Not applicable.

Informed Consent Statement: Not applicable.

Data Availability Statement: The data that support the findings of this study are available from the corresponding authors on a reasonable request. 
Acknowledgments: The support and resources from the Centre for High Performance Computing at the University of Utah are gratefully acknowledged.

Conflicts of Interest: The authors declare no conflict of interest.

\section{References}

1. Thorn, D.L.; Hoffmann, R. Delocalization in metallocycles. Nouv. J. Chim. 1979, 3, 39-45.

2. Elliot, G.P.; Roper, W.R.; Waters, J.M. Metallacyclohexatrienes or 'metallabenzenes'. Synthesis of osmabenzene derivatives and X-ray crystal structure of $\left[\mathrm{Os}(\mathrm{CSCHCHCHCH})(\mathrm{CO})\left(\mathrm{PPh}_{3}\right)_{2}\right]$. J. Chem. Soc. Chem. Commun. 1982, 811-813. [CrossRef]

3. Bleeke, J.R. Metallabenzenes. Chem. Rev. 2001, 101, 1205-1228. [CrossRef] [PubMed]

4. Wright, L.J. Metallabenzenes and metallabenzenoids. Dalton Trans. 2006, 1821-1827. [CrossRef]

5. Frogley, B.J.; Wright, L.J. Recent advances in metallaaromatic chemistry. Chem. Eur. J. 2018, 24, 2025-2038. [CrossRef]

6. Zhu, J.; Jia, G.; Lin, Z. Understanding nonplanarity in metallabenzene complexes. Organometallics 2007, 26, 1986-1995. [CrossRef]

7. Jia, G. Our journey to the chemistry of metallabenzynes. Organometallics 2013, 32, 6852-6866. [CrossRef]

8. Jia, G. Recent progress in the chemistry of osmium carbyne and metallabenzyne complexes. Coord. Chem. Rev. 2007, 251, 2167-2187. [CrossRef]

9. Jia, G. Progress in the chemistry of metallabenzynes. Acc. Chem. Res. 2004, 37, 479-486. [CrossRef]

10. Han, F.; Li, J.; Zhang, H.; Wang, T.; Lin, Z.; Xia, H. Reactions of osmabenzene with silver/copper acetylides: From metallabenzene to benzene. Chem. Eur. J. 2015, 21, 565-567. [CrossRef]

11. Wu, L.; Feng, L.; Zhang, H.; Liu, Q.; He, X.; Yang, F.; Xia, H. Synthesis and characterization of a novel dialdehyde and cyclic anhydride. J. Org. Chem. 2008, 73, 2883-2885. [CrossRef]

12. Zhang, H.; Feng, L.; Gong, L.; Wu, L.; He, G.; Wen, T.; Yang, F.; Xia, H. Synthesis and characterization of stable ruthenabenzenes starting from $\mathrm{HC}: \mathrm{CCH}(\mathrm{OH}) \mathrm{C}: \mathrm{CH}$. Organometallics 2007, 26, 2705-2713. [CrossRef]

13. Lin, R.; Zhang, H.; Li, S.; Wang, J.; Xia, H. New highly stable metallabenzenes via nucleophilic aromatic substitution reaction. Chem. Eur. J. 2011, 17, 4223-4231. [CrossRef]

14. Rickard, C.E.F.; Roper, W.R.; Woodgate, S.D.; Wright, L.J. Electrophilic aromatic substitution reactions of a metallabenzene: Nitration and halogenation of the osmabenzene $\left[\mathrm{Os}\{\mathrm{C}(\mathrm{SMe}) \mathrm{CHCHCHCH}\} \mathrm{I}(\mathrm{CO})\left(\mathrm{PPh}_{3}\right)_{2}\right]$. Angew. Chem. Int. Ed. 2000, 39, 766-768. [CrossRef]

15. Rickard, C.E.F.; Roper, W.R.; Woodgate, S.D.; Wright, L.J. Reaction between the thiocarbonyl complex, Os(CS)(CO)(PPh $)_{3}$, and propyne: Crystal structure of a new sulfur-substituted osmabenzene. J. Organomet. Chem. 2001, 623, 109-115. [CrossRef]

16. Xia, H.; He, G.; Zhang, H.; Wen, T.B.; Sung, H.H.Y.; Williams, I.D.; Jia, G. Osmabenzenes from the Reactions of $\mathrm{HC} \equiv \mathrm{CCH}(\mathrm{OH}) \mathrm{C} \equiv \mathrm{CH}$ with $\mathrm{OsX}_{2}\left(\mathrm{PPh}_{3}\right)_{3}(\mathrm{X}=\mathrm{Cl}, \mathrm{Br})$. J. Am. Chem. Soc. 2004, 126, 6862-6863. [CrossRef]

17. Hung, W.Y.; Zhu, J.; Wen, T.B.; Yu, K.P.; Sung, H.H.Y.; Williams, I.D.; Lin, Z.; Jia, G. osmabenzenes from the reactions of a dicationic osmabenzyne complex. J. Am. Chem. Soc. 2006, 128, 13742-13752. [CrossRef]

18. Gong, L.; Lin, Y.; He, G.; Zhang, H.; Wang, H.; Wen, T.B.; Xia, H. Synthesis and characterization of an air-stable p-osmaphenol. Organometallics 2008, 27, 309-311. [CrossRef]

19. Wang, T.; Li, S.; Zhang, H.; Lin, R.; Han, F.; Lin, Y.; Wen, T.B.; Xia, H. Annulation of metallabenzenes: From osmabenzene to osmabenzothiazole to osmabenzoxazole. Angew. Chem. Int. Ed. 2009, 48, 6453-6456. [CrossRef]

20. Clark, G.R.; Ferguson, L.A.; McIntosh, A.E.; Söhnel, T.; Wright, L.J. Functionalization of metallabenzenes through nucleophilic aromatic substitution of hydrogen. J. Am. Chem. Soc. 2010, 132, 13443-13452. [CrossRef]

21. Huang, J.; Lin, R.; Wu, L.; Zhao, Q.; Zhu, C.; Wen, T.B.; Xia, H. Synthesis, characterization, and electrochemical properties of bisosmabenzenes bridged by diisocyanides. Organometallics 2010, 29, 2916-2925. [CrossRef]

22. Wang, T.; Zhang, H.; Han, F.; Long, L.; Lin, Z.; Xia, H. Key Intermediates of iodine-mediated electrophilic cyclization: Isolation and characterization in an osmabenzene system. Angew. Chem. Int. Ed. 2013, 52, 9251-9255. [CrossRef]

23. Han, F.; Wang, T.; Li, J.; Zhang, H.; Zhang, L.; He, X.; Xia, H. Synthesis, structure, and reactivity of an osmacyclopentene complex. Organometallics 2014, 33, 5301-5307. [CrossRef]

24. Poon, K.C.; Liu, L.; Guo, T.; Li, J.; Sung, H.H.Y.; Williams, I.D.; Lin, Z.; Jia, G. Synthesis and characterization of rhenabenzenes. Angew. Chem. Int. Ed. 2010, 49, 2759-2762. [CrossRef]

25. Lin, R.; Lee, K.-H.; Poon, K.C.; Sung, H.H.Y.; Williams, I.D.; Lin, Z.; Jia, G. Synthesis of rhenabenzenes from the reactions of rhenacyclobutadienes with ethoxyethyne. Chem. Eur. J. 2014, 20, 14885-14899. [CrossRef]

26. Lin, R.; Lee, K.H.; Sung, H.H.Y.; Williams, I.D.; Lin, Z.; Jia, G. Rhenabenzenes and unexpected coupling products from the reactions of rhenacyclobutadienes with ethoxyethyne. Organometallics 2015, 34, 167-176. [CrossRef]

27. Jacob, V.; Weakley, T.J.R.; Haley, M.M. Rearrangement of a $\sigma$-2-(Cycloprop-2-enyl)vinyl- to an $\eta^{3}$-cyclopentadienylplatinum(II) complex. Selective protonolysis of the platinum-methyl bond. Organometallics 2002, 21, 5394-5400. [CrossRef]

28. Jacob, V.; Weakley, T.J.R.; Haley, M.M. Metallabenzenes and valence isomers. Synthesis and characterization of a platinabenzene. Angew. Chem. Int. Ed. 2002, 41, 3470-3473. [CrossRef]

29. Landorf, C.W.; Jacob, V.; Weakley, T.J.R.; Haley, M.M. Rational synthesis of platinabenzenes. Organometallics 2004, 23, 1174-1176. [CrossRef] 
30. Jacob, V.; Landorf, C.W.; Zakharov, L.N.; Weakley, T.J.R.; Haley, M.M. Platinabenzenes: Synthesis, properties, and reactivity studies of a rare class of metalla-aromatics. Organometallics 2009, 28, 5183-5190. [CrossRef]

31. Bleeke, J.R.; Behm, R. Synthesis, Structure, and reactivity of iridacyclohexadienone and iridaphenol complexes. J. Am. Chem. Soc. 1997, 119, 8503-8511. [CrossRef]

32. Gilbertson, R.D.; Weakley, T.J.R.; Haley, M.M. Direct synthesis of an iridabenzene from a nucleophilic 3-vinyl-1-cyclopropene. J. Am. Chem. Soc. 1999, 121, 2597-2598. [CrossRef]

33. Gilbertson, R.D.; Weakley, T.J.R.; Haley, M.M. Synthesis, characterization, and isomerization of an iridabenzvalene. Chem. Eur. J. 2000, 6, 437-441. [CrossRef]

34. Paneque, M.; Poveda, M.L.; Rendón, N.; Álvarez, E.; Carmona, E. The synthesis of iridabenzenes by the coupling of iridacyclopentadienes and olefins. Eur. J. Inorg. Chem. 2007, 2007, 2711-2720. [CrossRef]

35. Paneque, M.; Posadas, C.M.; Poveda, M.L.; Rendón, N.; Santos, L.L.; Álvarez, E.; Salazar, V.; Mereiter, K.; Oñate, E. Metallacycloheptatrienes of iridium(III): Synthesis and reactivity. Organometallics 2007, 26, 3403-3415. [CrossRef]

36. Vivancos, Á.; Paneque, M.; Poveda, M.L.; Álvarez, E. Building a parent iridabenzene structure from acetylene and dichloromethane on an iridium center. Angew. Chem. Int. Ed. 2013, 52, 10068-10071. [CrossRef]

37. Chase, D.T.; Zakharov, L.N.; Haley, M.M. Crystal structures of two unusual, high oxidation state, 16-electron iridabenzenes. Acta Crystallogr. Sect. E 2015, 71, 1315-1318. [CrossRef]

38. Fernández, I.; Frenking, G. Aromaticity in metallabenzenes. Chem. Eur. J. 2007, 13, 5873-5884. [CrossRef]

39. Huang, Y.Z.; Yang, S.Y.; Li, X.Y. An investigation of the aromaticity of transition metal heterocyclic complexes by conventional criteria and indices of aromaticity. J. Organomet. Chem. 2004, 689, 1050-1056. [CrossRef]

40. Mauksch, M.; Tsogoeva, S.B. Demonstration of “Möbius" aromaticity in planar metallacycles. Chem. Eur. J. 2010, 16, 7843-7851. [CrossRef]

41. De Proft, F.; Geerlings, P. Relative hardness as a measure of aromaticity. Phys. Chem. Chem. Phys. 2004, 6, 242-248. [CrossRef]

42. Zhang, H.; Lin, R.; Li, J.; Zhu, J.; Xia, H. Interconversion between Ruthenacyclohexadiene and Ruthenabenzene: A combined experimental and theoretical study. Organometallics 2014, 33, 5606-5609. [CrossRef]

43. Periyasamy, G.; Burton, N.A.; Hillier, I.H.; Thomas, J.M.H. Electron delocalization in the metallabenzenes: A computational analysis of ring currents. J. Phys. Chem. A 2008, 112, 5960-5972. [CrossRef] [PubMed]

44. Iron, M.A.; Lucassen, A.C.B.; Cohen, H.; van der Boom, M.E.; Martin, J.M.L. A Computational foray into the formation and reactivity of metallabenzenes. J. Am. Chem. Soc. 2004, 126, 11699-11710. [CrossRef]

45. Han, F.; Wang, T.; Li, J.; Zhang, H.; Xia, H. m-Metallaphenol: Synthesis and reactivity studies. Chem. Eur. J. 2014, 20, 4363-4372. [CrossRef]

46. Rzepa, H.S. Möbius aromaticity and delocalization. Chem. Rev. 2005, 105, 3697-3715. [CrossRef]

47. Fernández, I.; Frenking, G.; Merino, G. Aromaticity of metallabenzenes and related compounds. Chem. Soc. Rev. 2015, 44, 6452-6463. [CrossRef]

48. Wen, T.B.; Ng, S.M.; Hung, W.Y.; Zhou, Z.Y.; Lo, M.F.; Shek, L.-Y.; Williams, I.D.; Lin, Z.; Jia, G. Protonation and bromination of an osmabenzyne: Reactions leading to the formation of new metallabenzynes. J. Am. Chem. Soc. 2003, 125, 884-885. [CrossRef]

49. Chen, J.; Shi, C.; Sung, H.H.Y.; Williams, I.D.; Lin, Z.; Jia, G. Synthesis and characterization of rhenabenzyne complexes. Chem. Eur. J. 2012, 18, 14128-14139. [CrossRef]

50. Adamo, C.; Barone, V. Toward reliable density functional methods without adjustable parameters: The PBE0 model. J. Chem. Phys. 1999, 110, 6158-6170. [CrossRef]

51. Wadt, W.R.; Hay, P.J. Ab initio effective core potentials for molecular calculations. Potentials for main group elements Na to Bi. J. Chem. Phys. 1985, 82, 284-298. [CrossRef]

52. Schäfer, A.; Huber, C.; Ahlrichs, R. Fully optimized contracted Gaussian basis sets of triple zeta valence quality for atoms Li to Kr. J. Chem. Phys. 1994, 100, 5829-5835. [CrossRef]

53. Zubarev, D.Y.; Boldyrev, A.I. Developing paradigms of chemical bonding: Adaptive natural density partitioning. Phys. Chem. Chem. Phys. 2008, 10, 5207-5217. [CrossRef]

54. Tkachenko, N.V.; Boldyrev, A.I. Chemical bonding analysis of excited states using the adaptive natural density partitioning method. Phys. Chem. Chem. Phys. 2019, 21, 9590-9596. [CrossRef]

55. Tkachenko, N.V.; Zhang, X.W.; Qiao, L.; Shu, C.C.; Steglenko, D.; Muñoz-Castro, A.; Sun, Z.M.; Boldyrev, A.I. Spherical aromaticity of all-metal [Bi@In $\left.\mathrm{In}_{8} \mathrm{Bi}_{12}\right]^{3-/ 5-}$ clusters. Chem. Eur. J. 2020, 26, 2073-2079.

56. Tkachenko, N.V.; Boldyrev, A.I. Multiple local $\sigma$-aromaticity of nonagermanide clusters. Chem. Sci. 2019, 10, 5761-5765. [CrossRef]

57. Liu, C.; Tkachenko, N.V.; Popov, I.A.; Fedik, N.; Min, X.; Xu, C.Q.; Li, J.; McGrady, J.E.; Boldyrev, A.I.; Sun, Z.M. Structure and bonding in $\left[\mathrm{Sb}_{\mathrm{In}} \mathrm{Sb}_{12}\right]^{3-}$ and [Sb@In $\left.\mathrm{Sb}_{12}\right]^{5-}$. Angew. Chem. Int. Ed. 2019, 58, 8367-8371. [CrossRef]

58. Xu, H.L.; Popov, I.A.; Tkachenko, N.V.; Wang, Z.C.; Muñoz-Castro, A.; Boldyrev, A.I.; Sun, Z.M. o-Aromaticity-induced stabilization of heterometallic supertetrahedral clusters $\left[\mathrm{Zn}_{6} \mathrm{Ge}_{16}\right]^{4-}$ and $\left[\mathrm{Cd}_{6} \mathrm{Ge}_{16}\right]^{4-}$. Angew. Chem. Int. Ed. 2020, 59, 1728617290. [CrossRef]

59. Zhang, W.Q.; Tkachenko, N.V.; Qiao, L.; Boldyrev, A.I.; Sun, Z.M. Synthesis and structure of binary copper/silver-arsenic clusters derived from Zintl ion $\mathrm{As}_{7}{ }^{3-}$. Chin. J. Chem. 2021, in press. [CrossRef]

60. Wang, Z.C.; Tkachenko, N.V.; Qiao, L.; Matito, E.; Muñoz-Castro, A.; Boldyrev, A.I.; Sun, Z.M. All-metal $\sigma$-antiaromaticity in dimeric cluster anion $\left\{\left[\mathrm{CuGe}{ }_{9} \mathrm{Mes}\right]_{2}\right\}^{4-}$. Chem. Commun. 2020, 56, 6583-6586. [CrossRef] 
61. Tkachenko, N.V.; Steglenko, D.; Fedik, N.; Boldyreva, N.M.; Minyaev, R.M.; Minkin, V.I.; Boldyrev, A.I. Superoctahedral two-dimensional metallic boron with peculiar magnetic properties. Phys. Chem. Chem. Phys. 2019, 21, $19764-19771$.

62. Steglenko, D.V.; Tkachenko, N.V.; Boldyrev, A.I.; Minyaev, R.M.; Minkin, V.I. Stability, electronic, and optical properties of two-dimensional phosphoborane. J. Comput. Chem. 2020, 41, 1456-1463. [CrossRef]

63. Popov, I.A.; Bozhenko, K.V.; Boldyrev, A.I. Is graphene aromatic? Nano Res. 2012, 5, 117-123. [CrossRef]

64. Kuznetsov, A.E.; Boldyrev, A.I.; Li, X.; Wang, L.S. On the Aromaticity of Square Planar $\mathrm{Ga}_{4}{ }^{2-}$ and $\mathrm{In}_{4}{ }^{2-}$ in $\mathrm{Gaseous} \mathrm{NaGa}_{4}{ }^{-}$and $\mathrm{NaIn}_{4}{ }^{-}$clusters. J. Am. Chem. Soc. 2001, 123, 8825-8831. [CrossRef]

65. Boldyrev, A.I.; Wang, L.S. All-metal aromaticity and antiaromaticity. Chem. Rev. 2005, 105, 3716-3757. [CrossRef]

66. Casademont-Reig, I.; Ramos-Cordoba, E.; Torrent-Sucarrat, M.; Matito, E. How do the Hückel and baird rules fade away in annulenes? Molecules 2020, 25, 711. [CrossRef]

67. Yanai, T.; Tew, D.P.; Handy, N.C. A new hybrid exchange-Correlation functional using the Coulomb-attenuating method (CAM-B3LYP). Chem. Phys. Lett. 2004, 393, 51-57. [CrossRef]

68. Chen, Z.; Wannere, C.S.; Corminboeuf, C.; Puchta, R.; von Schleyer, P.R. Nucleus-independent chemical shifts (NICS) as an aromaticity criterion. Chem. Rev. 2005, 105, 3842-3888. [CrossRef] [PubMed]

69. Frisch, M.J.; Trucks, G.W.; Schlegel, H.B.; Scuseria, G.E.; Robb, M.A.; Cheeseman, J.R.; Scalmani, G.; Barone, V.; Petersson, G.A.; Nakatsuji, H.; et al. Gaussian 16, Revision B.01; Gaussian, Inc.: Wallingford, CT, USA, 2016.

70. Islas, R.; Heine, T.; Merino, G. The induced magnetic field. Acc. Chem. Res. 2012, 45, 215-228. [CrossRef] [PubMed]

71. Heine, T.; Corminboeuf, C.; Seifert, G. The magnetic shielding function of molecules and Pi-electron delocalization. Chem. Rev. 2005, 105, 3889-3910. [CrossRef] [PubMed]

72. Merino, G.; Heine, T.; Seifert, G. The induced magnetic field in cyclic molecules. Chem. A Eur. J. 2004, 10, 4367-4371. [CrossRef]

73. Amsterdam Density Functional (ADF 2019) Code. 2020. Available online: http:/ / www.scm.com (accessed on 20 September 2021).

74. Baranac-Stojanović, M. New insight into the anisotropic effects in solution-state NMR spectroscopy. RSC Adv. 2014, 4, 308-321. [CrossRef]

75. Klod, S.; Kleinpeter, E. Ab initio calculation of the anisotropy effect of multiple bonds and the ring current effect of arenesapplication in conformational and configurational analysis. J. Chem. Soc. Perkin Trans. 2001, 2, 1893-1898.

76. Charistos, N.D.; Papadopoulos, A.G.; Sigalas, M.P. Interpretation of electron delocalization in benzene, cyclobutadiene, and borazine based on visualization of individual molecular orbital contributions to the induced magnetic field. J. Phys. Chem. A 2014, 118, 1113-1122. [CrossRef]

77. Lenthe, E.V.; Baerends, E.J.; Snijders, J.G. Relativistic total energy using regular approximations. J. Chem. Phys. 1994, 101, 9783-9792. [CrossRef]

78. Furukawa, S.; Fujita, M.; Kanatomi, Y.; Minoura, M.; Hatanaka, M.; Morokuma, K.; Ishimura, K.; Saito, M. Double aromaticity arising from $\sigma$ - and $\pi$-rings. Commun. Chem. 2018, 1, 60. [CrossRef]

79. Morao, I.; Cossío, F.P. A Simple ring current model for describing in-plane aromaticity in pericyclic reactions. J. Org. Chem. 1999, 64, 1868-1874. [CrossRef]

80. Tsipis, A.C.; Depastas, I.G.; Tsipis, C.A. Diagnosis of the $\sigma-, \pi$ - and $(\sigma+\pi)$-aromaticity by the shape of the NICS zz scan curves and symmetry-based selection rules. Symmetry 2010, 2, 284-319. [CrossRef]

81. Muñoz-Castro, A. Magnetic response properties of coinage metal macrocyles. Insights into the induced magnetic field through the analysis of $\left[\mathrm{Cu}_{5}(\mathrm{Mes})_{5}\right],\left[\mathrm{Ag}_{4}(\mathrm{Mes})_{4}\right]$, and $\left[\mathrm{Au}_{5}(\mathrm{Mes})_{5}\right]$ (Mes = 2,4,6-Me3C6H2). J. Phys. Chem. C 2012, 116, 17197-17203. [CrossRef]

82. Moncho, S.; Autschbach, J. Molecular orbital analysis of the inverse halogen dependence of nuclear magnetic shielding in LaX $3, \mathrm{X}$ = F, Cl, Br, I. Magn. Reson. Chem. 2010, 48, S76-S85. [CrossRef]

83. Viesser, R.V.; Ducati, L.C.; Autschbach, J.; Tormena, C.F. Effects of stereoelectronic interactions on the relativistic spin-orbit and paramagnetic components of the ${ }^{13}$ C NMR shielding tensors of dihaloethenes. Phys. Chem. Chem. Phys. 2015, 17, 19315-19324. [CrossRef]

84. von Schleyer, P.R.; Jiao, H. What is aromaticity? Pure Appl. Chem. 1996, 68, 209-218. [CrossRef] 